OPEN ACCESS

Edited by:

Zheng Ruan,

Nanchang University, China

Reviewed by:

Wenkai Ren,

South China Agricultural University,

China

Tiejun $\mathrm{Li}$,

Chinese Academy of Sciences,

China

${ }^{*}$ Correspondence:

Wenjie Tang

wenhan28@126.com

tThese authors have contributed equally to this work

Specialty section:

This article was submitted to

Food Microbiology,

a section of the journal

Frontiers in Microbiology

Received: 06 September 2021

Accepted: 11 October 2021

Published: 28 October 2021

Citation:

Diao H, Yan J, Li S, Kuang S, Wei X, Zhou M, Zhang J, Huang $C$, He P and Tang W (2021) Effects of Dietary Zinc Sources on Growth

Performance and Gut Health of Weaned Piglets.

Front. Microbiol. 12:771617.

doi: 10.3389/fmicb.2021.771617

\section{Effects of Dietary Zinc Sources on Growth Performance and Gut Health of Weaned Piglets}

\author{
Hui Diao ${ }^{1 \dagger}$, Jiayou Yan ${ }^{1 \dagger}$, Shuwei $\mathrm{Li}^{1,2 t}$, Shengyao Kuang ${ }^{3}$, Xiaolan Wei ${ }^{1}$, Mengjia Zhou', \\ Jinxiu Zhang ${ }^{1}$, Chongbo Huang ${ }^{1}$, Peng $\mathrm{He}^{1}$ and Wenjie Tang ${ }^{1 *}$
}

'Animal Breeding and Genetics Key Laboratory of Sichuan Province, Sichuan Academy of Animal Science, Chengdu, China, ${ }^{2}$ Sichuan Animtech Biology Development Co., Ltd, Chengdu, China, ${ }^{3}$ Livestock and Poultry Biological Products Key Laboratory of Sichuan Province, Sichuan Animtech Feed Co., Ltd, Chengdu, China

The present study aimed to investigate the effects of dietary zinc sources on the growth performance and gut health of weaned piglets. In total, 96 Duroc $\times$ Landrace $\times$ Yorkshire (DLY) weaned piglets with an initial average body weight of $8.81 \pm 0.42 \mathrm{~kg}$ were divided into four groups, with six replicates per treatment and four pigs per replicate. The dietary treatment groups were as follows: (1) control group, basal diet; (2) zinc sulphate (ZnSO4) group, basal diet $+100 \mathrm{mg} / \mathrm{kg}$ ZnSO4; (3) glycine zinc (Gly-Zn) group, basal diet $+100 \mathrm{mg}$ / $\mathrm{kg}$ Gly-Zn and (4) zinc lactate group, and basal diet $+100 \mathrm{mg} / \mathrm{kg}$ zinc lactate. The whole trial lasted for 28 days. Decreased F/G was noted in the Gly-Zn and zinc lactate groups $(p<0.05)$. The zinc lactate group had a lower diarrhea rate than the control group $(p<0.05)$. Moreover, the ZnSO4, Gly-Zn, and zinc lactate groups had significantly higher apparent total tract digestibility of dry matter (DM), crude protein (CP), ether extract (EE), crude ash, and zinc than the control group $(p<0.05)$. The Gly-Zn and zinc lactate groups had higher jejunal villus height and a higher villus height:crypt depth ratio than the control group ( $p<0.05)$. In addition, the $\mathrm{ZnSO} 4$, Gly- $\mathrm{Zn}$ and zinc lactate groups had a significantly lower mRNA expression level of jejunal ZRT/IRT-like protein 4 (ZIP4) and higher mRNA expression level of jejunal interleukin-1 $\beta(\mathrm{IL}-1 \beta)$ than the control group $(p<0.05)$. The mRNA expression level of jejunal zinc transporter 2 (ZNT2) was higher and that of jejunal $\mathrm{Bcl}$-2-associated X protein (Bax) was lower in the Gly-Zn and zinc lactate groups than in the control group $(p<0.05)$. Moreover, the zinc lactate group had a higher count of Lactobacillus spp. in the cecal digesta and higher mRNA expression levels of jejunal occludin and mucin 2 (MUC2) than the control group $(p<0.05)$. In conclusion, dietary supplementation with $100 \mathrm{mg} / \mathrm{kg}$ ZnSO4, Gly-Zn, or zinc lactate could improve the growth performance and gut barrier function of weaned piglets. Dietary supplementation with organic zinc, particularly zinc lactate, had the best effect.

Keywords: zinc source, growth performance, digestibility, gut health, weaned piglets 


\section{INTRODUCTION}

In the weaning stage, piglets have weak cerebral cortex development and high metabolism and face high nutritional, environmental, and psychological stress, resulting in changes in intestinal digestion and absorption, immunity, and behavior, which manifest as diarrhea, growth retardation, and even death (Campbell et al., 2013). In recent years, weaning stress of piglets has been found to damage the intestinal mucosal barrier function of piglets and their innate immune response to pathogenic bacteria (Hu et al., 2013; Mclamb et al., 2013). The intestine is not only the main organ for the digestion and absorption of nutrients but also the largest organ in the immune system of animals. It has two critical functions: acting as a selective filter for essential nutrients and acting as a barrier against harmful substances (Karl Kunzelmann, 2002; Blikslager et al., 2007). Intestinal barrier dysfunction can cause intestinal microorganisms and endotoxins to break through the intestinal barrier and enter other organs and the circulatory system, resulting in intestinal infections and diseases, such as inflammatory bowel disease, food allergy, diarrhea, and ischemic disease (Torsten et al., 2001; Turner, 2006).

Zinc is an essential trace element that plays a crucial role in several biological processes (Bonaventura et al., 2015). It is an activator or a component of various enzymes in animals and is involved in intracellular signal transduction and cell proliferation, thereby affecting cellular function, acid-base balance, oxidation resistance, immune capacity, and reproduction (Vallee and Falchuk, 1993; Andreini et al., 2006). Moreover, zinc is beneficial for the regeneration of injured intestinal epithelial tissue and is thus necessary for normal intestinal barrier function (Alam et al., 1994). Dietary supplementation with zinc has been shown to reduce intestinal permeability and prevent the loss of intestinal integrity as a result of weaning, heat stress, malnutrition, and inflammatory bowel disease (Rodriguez et al., 1996; Zhang and Guo, 2009; Fernandez et al., 2014). Given these biological functions, zinc may be an attractive feed additive for improving gut health.

Dietary supplementation with inorganic or organic zinc is a common industry practice for meeting the dietary requirements of animals. Inorganic zinc sources, such as zinc sulphate (ZnSO4), have been used as the main nutrient source in feed for a long time (Sandra et al., 2020). In organic zinc sources, zinc binds to organic ligands, typically an organic acid, amino acid, or protein. Organic zinc sources have a relatively higher bioavailability than inorganic ones, allowing lower concentrations to be added to feed (Pearce et al., 2015; Li et al., 2018). Dietary supplementation with organic zinc has been found to improve the growth performance and intestinal health of animals (Levkut et al., 2017; Song et al., 2017; Yan et al., 2017). Zinc lactate, an organic zinc source, has been used as a new feed additive in production practices; however, the effect of zinc lactate on the intestinal health of weaned piglets has not been systematically studied. Moreover, the effects of zinc lactate on the growth performance and intestinal health of piglets need to be compared with those of other zinc sources commonly used in livestock production. Therefore, the objective of the present study was to systematically assess the effects of dietary zinc sources [ZnSO4, glycine zinc (Gly- $\mathrm{Zn})$ and zinc lactate] on the growth performance, intestinal development, digestion and absorption, and intestinal barrier function of weaned piglets in order to further understand the mechanisms underlying the regulatory effects of different zinc sources on intestinal health.

\section{MATERIALS AND METHODS}

\section{Animals, Management, and Diets}

ZnSO4 was provided by Chengdu Shuxing Feed Co., Ltd. (No 147 Qingpu Road, Shouan, Sichuan, China). Gly-Zn was provided by Sichuan jilongda Biotechnology Group Co., Ltd. (No 111 Jinxing Road, Guanghan, Sichuan, China). Zinc lactate was provided by Sichuan Animtech Feed Co., Ltd. (No.7 Niusha Road, Chengdu, Sichuan, China).

In total, 96 healthy Duroc $\times$ Landrace $\times$ Yorkshire $($ DLY) weaned piglets ( 28 days old) with an initial average body weight of $8.81 \pm 0.42 \mathrm{~kg}$ were randomly divided into four groups, with six replicates per treatment and four pigs per replicate, according to their initial body weight and sex. The dietary treatment groups were as follows: (1) control group, basal diet; (2) ZnSO4 group, basal diet $+100 \mathrm{mg} / \mathrm{kg} \mathrm{ZnSO}$; (3) Gly-Zn group, basal diet $+100 \mathrm{mg} / \mathrm{kg} \mathrm{Gly-Zn;} \mathrm{and} \mathrm{(4)} \mathrm{zinc} \mathrm{lactate} \mathrm{group,} \mathrm{basal} \mathrm{diet}$ $+100 \mathrm{mg} / \mathrm{kg}$ zinc lactate. The whole trial lasted for 28 days. On days 25-28, the digestion test was performed using acid insoluble ash (AIA) as an endogenous indicator.

The basal diets were formulated by using corn and soybean meal as the main ingredients. The experimental diet was prepared according to the nutrient recommendations of NRC (2012) for pigs weighing 7-11 kg (Table 1). No antibiotics were used in any diet. Piglets were penned by replicates in sties $\left(1.6 \times 1.5 \mathrm{~m}^{2}\right)$. The room temperature and relative humidity were controlled during the experimental period. All the piglets had ad libitum access to both feed and water. The health status of each pig was checked once a day.

\section{Sample Collection}

Using the quartering method, about $150 \mathrm{~g}$ of the experimental diet was taken for each treatment and stored in a refrigerator at $-20^{\circ} \mathrm{C}$ until the analysis of nutrient contents. Fecal samples were collected from days 25 to 28 of the experiment to determine the apparent total tract digestibility (ATTD). After each collection, a few drops of toluene and $10 \%$ hydrochloric acid were added to the samples for antisepsis and nitrogen fixation. The fecal samples collected from days 25 to 28 from each replicate were thoroughly mixed and dried in a forced air oven at $60^{\circ} \mathrm{C}$ for $72 \mathrm{~h}$. Following this, the dried samples were smashed and stored at $-20^{\circ} \mathrm{C}$ to measure the nutrient contents.

At the end of day 28 of the experiment, one piglet with an average body weight was selected in each pen, anesthetized with $10 \mathrm{mg} / \mathrm{kg}$ body weight of Zoletil 50 (Beijing PET Technology Co., Ltd, Beijing, China), and slaughtered by exsanguination. Then, the abdomen was opened and the intestinal segments were rapidly separated. Following this, the intact duodenum, 
TABLE 1 | Composition and nutrient level of basic diet (air dry basis \%).

\begin{tabular}{|c|c|c|c|}
\hline Ingredient & Content & Composition & Nutrient content \\
\hline Corn & 27.79 & $\begin{array}{l}\text { Calculated } \\
\text { Composition }\end{array}$ & \\
\hline Extruded corn & 28.61 & DE (MJ/kg) & 3.55 \\
\hline $\begin{array}{l}\text { Dehulled soybean } \\
\text { meal }\end{array}$ & 10.33 & Crude protein & 19.59 \\
\hline Extruded soybean & 4.50 & Calcium & 0.81 \\
\hline Fish meal & 0.50 & Total phosphorus & 0.57 \\
\hline Whey powder & 8.00 & $\begin{array}{l}\text { Available } \\
\text { phosphorus }\end{array}$ & 0.37 \\
\hline $\begin{array}{l}\text { Soybean protein } \\
\text { concentrate }\end{array}$ & 12.00 & Lys & 1.36 \\
\hline Soybean oil & 1.90 & Met+Cys & 0.75 \\
\hline Sucrose & 3.50 & Thr & 0.79 \\
\hline Limestone & 0.91 & Trp & 0.23 \\
\hline $\begin{array}{l}\text { Dicalcium } \\
\text { phosphate }\end{array}$ & 0.74 & $\begin{array}{l}\text { Analyzed } \\
\text { composition }\end{array}$ & \\
\hline $\mathrm{NaCl}$ & 0.25 & Crude protein & 19.70 \\
\hline L-Lys-HCI (78\%) & 0.38 & Crude ash & 4.80 \\
\hline DL-Met (99\%) & 0.17 & Dry matter & 90.90 \\
\hline Trp (98\%) & 0.05 & Ether extraction & 6.20 \\
\hline Thr (98.5\%) & 0.02 & Zinc $^{3}$ & 0.002 \\
\hline Chloride choline & 0.10 & & \\
\hline Vitamin premix ${ }^{1}$ & 0.05 & & \\
\hline Mineral premix² & 0.20 & & \\
\hline Total & 100.00 & & \\
\hline
\end{tabular}

The premix provides following per kg diet:VA 5512IU, VD32250 IU, VE $24 \mathrm{mg}$, VK3 $3 \mathrm{mg}$, VB2 $6 \mathrm{mg}$, VB6 $3 \mathrm{mg}$, VB12 $24 \mu \mathrm{g}$, folic acid $1.2 \mathrm{mg}$, nicotinic acid $14 \mathrm{mg}$, biotin $150 \mu \mathrm{g}, \mathrm{D}$-pantothenic acid $15 \mathrm{mg}$.

${ }^{2}$ The premix provides following per $\mathrm{kg}$ diet: Fe $100 \mathrm{mg}$, Cu 6mg, Mn 4mg, I0.14mg, Se $0.3 \mathrm{mg}$.

${ }^{3}$ Analyzed zinc content of experimental diets were as follows: $0.002 \%$ (Control group), 0.013\% (ZnSO4 group), 0.012\% (Gly-Zn group), 0.012\% (Zinc lactate group), respectively.

jejunum, and ileum were taken and stored in $4 \%$ paraformaldehyde solution for intestinal morphology analysis and goblet cell number determination. The cecal digesta was then collected into sterile EP tubes for determining the bacteria count. Finally, the jejunal mucosa were separated for measuring intestinal development and barrier-related gene expression levels and immediately stored at $-80^{\circ} \mathrm{C}$.

\section{Growth Performance}

The body weight of each pig was recorded on days 0 and 28; weighing was performed before the pigs were fed. During the experiment, the amount of feed offered daily and the quantity remaining in the feeder the next morning were accurately recorded for each pen. Feed consumption was calculated as the amount of feed offered daily - the quantity remaining in the feeder the next morning - the amount of waste material. The values were used to calculate the average daily gain (ADG) and average daily feed intake (ADFI). The feed-to-gain ratio $(\mathrm{F} / \mathrm{G})$ was calculated on the basis of the ADG and ADFI values.

\section{Diarrhea Rate}

Diarrhea scores of all the piglets were recorded each afternoon for 28 days according to the following scoring system: $0=$ normal, firm feces; 1 =possible slight diarrhea, soft and formed feces;
$2=$ moderate diarrhea, unformed and slightly fluid feces, and $3=$ severe diarrhea, very watery feces (Hart and Dobb, 1988). Pigs with a score of 2 or 3 were considered to have diarrhea. The diarrhea rate was calculated using the following formula: diarrhea rate $(\%)=$ number of pigs with diarrhea in each pen/ (number of pigs $\times$ total observation days) $\times 100$ (Huang et al., 2004).

\section{Histological Measurements}

The duodenum, jejunum, and ileum, which were fixed in $4 \%$ paraformaldehyde solution for $8-24 \mathrm{~h}$, were dehydrated, made transparent, and embedded to prepare paraffin sections with a thickness of $5 \mu \mathrm{m}$. Following this, the sections of the intestinal samples were stained with hematoxylin and eosin. Then, 10 well-oriented slices were selected for each sample and photographed for morphometric variables detection. The distance from the villus tip to the crypt mouth (villus height) and that from the crypt mouth to the base (crypt depth) was measured using an image processing and analysis system (Media Cybernetics, Bethesda, MD, United States). Moreover, the number of jejunal goblet cells was counted using an Olympus optical microscope after histochemical staining with Alcian blue and periodic acid-Schiff (Ab-PAS) stains (Kunert et al., 2002).

\section{Apparent Total Tract Digestibility}

Samples of the feed and feces were assessed to measure the contents of zinc (Chinese National Standard, GB/T 138852017), crude ash (method 942.05, AOAC, 1995), CP (method 990.03, AOAC, 1995), EE (method 945.16, AOAC, 1995), and DM (method 930.15, AOAC, 1995). The ATTD was measured using AIA as an endogenous indicator. AIA in diets and feces samples were determined by a method described by Chinese National Standard (GB/T 23742). ATTD was calculated using previously published formulae (Diao et al., 2017).

\section{Total RNA Extraction, Reverse Transcription Reaction, and Real-Time Quantitative PCR}

Total RNA was separated from frozen jejunal mucosa using TRIzol reagent (Takara Bio Inc., Dalian, China), according to the manufacturer's instructions. Following this, the RNA quality and purity were assessed by electrophoresis on $0.1 \%$ agarose gels. Subsequently, eligible RNA samples were reverse transcribed into complementary DNA using the PrimeScript ${ }^{\mathrm{TM}}$ Reverse Transcription Reagent Kit (Takara Bio Inc., Dalian, China). For the quantification of intestinal development-related genes (IGF-1, insulin-like growth factor 1; EGF, epidermal growth factor), cell apoptosis-related genes (Bcl-2, B-cell lymphoma/leukemia-2; $\mathrm{Bax}, \mathrm{Bcl}-2$-associated $\mathrm{X}$ protein), intestinal digestion- and absorption-related genes (SGLT-1, sodium/glucose cotransporter 1; GLUT-2, glucose transporter type $2 ; \mathrm{SLC}_{7} \mathrm{~A}_{1}$, solute carrier family $7 ; \mathrm{ZNT} 1$, zinc transporter 1; ZNT2, zinc transporter 2; ZIP4, ZRT/IRT-like protein 4), and intestinal barrier-related genes (MUC1, mucin 1; MUC2, mucin 2; occludin; IL-10, interleukin-10; IL-1 $\beta$, interleukin-1 $\beta$ ), real-time PCR was performed using the CFX96 Real-Time 
TABLE 2 | Primer sequences and annealing temperature of pigs.

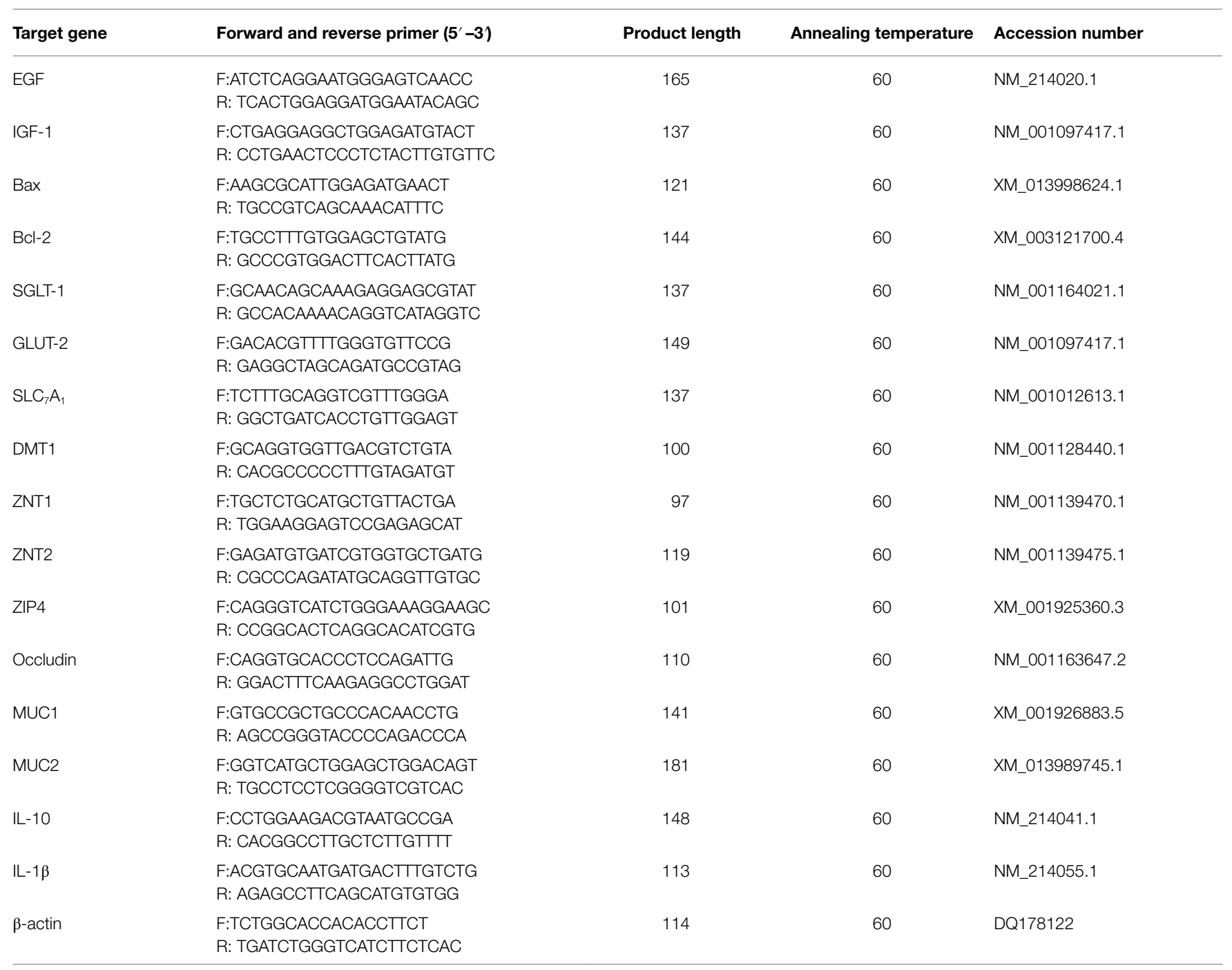

PCR Detection System (Bio-Rad Laboratories, Richmond, CA, United States), according to a previously published method (Zhao et al., 2015). A $10 \mu \mathrm{l}$ quantitative fluorescent PCR reaction volume was used in the present study; it consisted of $0.5 \mu \mathrm{l}$ upstream primer, $0.5 \mu \mathrm{l}$ downstream primer, $1 \mu \mathrm{l}$ cDNA, $3 \mu \mathrm{l}$ RNase-free $\mathrm{H}_{2} \mathrm{O}$, and $5 \mu \mathrm{l}$ SYBR Premix Ex Taq ${ }^{\mathrm{TM}}$. The reaction cycle conditions were as follows: $30 \mathrm{~s}$ at $95^{\circ} \mathrm{C}$, $10 \mathrm{~s}$ at $95^{\circ} \mathrm{C}$, and $25 \mathrm{~s}$ at $60^{\circ} \mathrm{C}$ for a total of 39 cycles. Primer sequences are shown in Table 2 ; the primers were commercially synthesized by Invitrogen (Shanghai, China). The relative expression level of each gene in the jejunum was computed using $\beta$-actin as the reference gene.

\section{Microbial Population Determination}

Digesta from the cecum were collected, and bacterial DNA was extracted using commercial stool DNA kits (Omega Bio-Tek, Doraville, CA, United States). Fluorescent oligonucleotide probes and primers for total bacteria, Lactobacillus spp., Escherichia coli., Bifidobacterium spp., and Bacillus spp. were acquired in accordance with previous reports
(Table 3) for the quantitative detection of the aforementioned bacteria (Fierer et al., 2005; Qi et al., 2011), which were commercially synthesized by Invitrogen (Shanghai, China). Quantitative real-time PCR was performed using the CFX96 Real-Time PCR Detection System (Bio-Rad Laboratories, Richmond, CA, United States) with optical-grade 96-well plates. A $25 \mu \mathrm{l}$ reaction mixture was used to determine the total bacterial count, and a $20 \mu$ l reaction mixture was used to determine the counts of Lactobacillus spp., E. coli., Bifidobacterium spp., and Bacillus spp. The PCR conditions and calculation method were in accordance with those reported in a previous study (Qi et al., 2011).

\section{Statistical Analysis}

The experimental data have been tested for normality prior to one-way ANOVA was made using SAS software (version 8.2, SAS Inst. Inc., Cary, NC). When the data were recognized as normally distributed and exhibited homogeneity of variance, data were analyzed by one-way ANOVA and Duncan's multiple comparison. For data analysis, each pen was considered as an 
TABLE 3 | Primes and probes for real-time PCR of bacteria.

\begin{tabular}{|c|c|c|}
\hline Items & Primer/probe name and sequence $\left(5^{\prime}-3\right)$ & Product length/bp \\
\hline Escherichia coli & $\begin{array}{l}\text { DC-F,CATGCCGCGTGTATGAAGAA } \\
\text { DC-R,CGGGTAACGTCAATGAGCAAA } \\
\text { DC-P,(FMA)AGGTATTAACTITACTCCCTTCCTC(BHQ-1) }\end{array}$ & 96 \\
\hline Lactobacillus & $\begin{array}{l}\text { RS-F,GAGGCAGCAGTAGGGAATCTTC } \\
\text { RS-R,CAACAGTTACTCTGACACCCGTTCTTC } \\
\text { RS-P,(FMA)AAGAAGGGTITCGGCTCGTAAAACTCTGTT(BHQ-1) }\end{array}$ & 126 \\
\hline Bifidobacterium & $\begin{array}{l}\text { SQ-F,CGCGTCCGGTGTGAAAG } \\
\text { SQ-R,CTTCCCGATATCTACACATTCCA } \\
\text { SQ-P, (FMA) ATTCCACCGTTACACCGGGAA(BHQ-1) }\end{array}$ & 121 \\
\hline Bacillus & $\begin{array}{l}\text { YB-F,GCAACGAGCGCAACCCTTGA } \\
\text { YB-R,TCATCCCCACCTTCCTCCGGT } \\
\text { YB-P, (FMA)CGGTTGTCACCGGCAGTCACCT(BHQ-1) }\end{array}$ & 92 \\
\hline Total bacteria & $\begin{array}{l}\text { Eub338F,ACTCCTACGGGAGGCAGCAG } \\
\text { Eub518R,ATTACCGCGGCTGCTGG }\end{array}$ & 200 \\
\hline
\end{tabular}

experimental unit. $p$ values $<0.05$ were considered statistically significant. Results are expressed as the means and SEMs.

\section{RESULTS}

\section{Growth Performance and Diarrhea Rate}

The effects of dietary zinc sources on the growth performance and diarrhea rate in weaned piglets are shown in Table 4. Compared with the control group, the $F / G$ decreased in the Gly- $\mathrm{Zn}$ and zinc lactate groups from days 0 to 28 $(p<0.05)$. However, a lower diarrhea rate was observed only in the zinc lactate group $(p<0.05)$. The ADG tended to be higher in the $\mathrm{ZnSO} 4, \mathrm{Gly}-\mathrm{Zn}$, and zinc lactate groups than in the control group $(p=0.053)$. No differences were observed in the ADFI among the four groups during the experimental period $(p>0.05)$.

\section{Apparent Total Tract Digestibility}

The effects of dietary zinc sources on the ATTD in weaned piglets are shown in Table 5. The ATTD of DM, CP, EE, and crude ash was significantly higher in the $\mathrm{ZnSO} 4$, Gly- $\mathrm{Zn}$, and zinc lactate groups than in the control group $(p<0.05)$. The ATTD of zinc significantly differed among the three groups receiving dietary zinc supplementation; it was the highest in the zinc lactate group, followed by the Gly- $\mathrm{Zn}$ and $\mathrm{ZnSO} 4$ groups $(p<0.05)$.

\section{Relative mRNA Expression Levels of Jejunal Transporters}

As shown in Figure 1, the mRNA expression level of jejunal ZIP4 was significantly lower in the $\mathrm{ZnSO} 4$, Gly-Zn, and zinc lactate groups than in the control group $(p<0.05)$. The mRNA expression of jejunal ZNT2 was higher in the Gly-Zn and zinc lactate groups than in the control group $(p<0.05)$. However, the mRNA expression level of jejunal ZNT2 did not differ significantly between the $\mathrm{ZnSO} 4$ and control groups $(p>0.05)$. The mRNA expression level of jejunal ZNT1 tended to be higher in the $\mathrm{ZnSO}$, Gly-Zn, and zinc lactate groups than in the control group $(p=0.067)$. However, the mRNA expression level of jejunal GLUT-2 tended to be higher only in the Gly- $\mathrm{Zn}$ and zinc lactate groups than in the control group $(p=0.064)$. Moreover, the mRNA expression levels of jejunal SGLT-1 and $\mathrm{SLC}_{7} \mathrm{~A}_{1}$ did not differ among the four groups $(p>0.05)$.

\section{Intestinal Morphology}

The villus height, crypt depth, and goblet cell number in small intestinal tissues are expressed in Table 6 and Figure 2. The jejunal villus height and villus height:crypt depth ratio were higher in the Gly-Zn and zinc lactate groups than in the control group $(p<0.05)$. The numbers of goblet cells in the ileum $(p=0.064)$ and the villus height of the duodenum $(p=0.094)$ and ileum $(p=0.060)$ tended to be higher in the zinc lactate group than in the control group. In addition, the jejunal crypt depth tended to be lower in the $\mathrm{ZnSO} 4$ and zinc lactate groups than in the control group $(p=0.079)$.

\section{Relative mRNA Expression Levels of Intestinal Development-Related Genes}

The mRNA expression levels of intestinal development-related genes in the piglets are summarized in Figure 3. The Gly-Zn and zinc lactate groups had a lower mRNA expression level of jejunal Bax than the control group $(p<0.05)$. However, the mRNA expression level of jejunal Bax did not differ significantly between the $\mathrm{ZnSO} 4$ and control groups $(p>0.05)$. Moreover, the mRNA expression levels of jejunal Bcl-2, EGF, and IGF-1 did not differ among the four groups $(p>0.05)$.

\section{Intestinal Barrier Function}

As shown in Figure 4, the zinc lactate group had a higher mRNA expression level of the jejunal occludin gene than the control group $(p<0.05)$. Moreover, the Gly- $\mathrm{Zn}$ and zinc lactate groups had a higher mRNA expression level of the jejunal occludin than the $\mathrm{ZnSO} 4$ group $(p<0.05)$. The mRNA expression level of jejunal IL-1 $\beta$ was higher in the $\mathrm{ZnSO} 4$, 
TABLE 4 | Effect of dietary zinc sources on the growth performance and diarrhea rate in weaned piglets.

\begin{tabular}{|c|c|c|c|c|c|c|}
\hline Items & Control & ZnSO4 & Gly-Zn & $\begin{array}{c}\text { Zinc } \\
\text { lactate }\end{array}$ & SEM & $P$ values \\
\hline $\begin{array}{l}\text { Initial BW, } \\
\text { kg }\end{array}$ & 8.68 & 8.92 & 8.86 & 8.82 & 0.212 & 0.873 \\
\hline $\begin{array}{l}\text { 28-day } \\
\text { BW, kg }\end{array}$ & 17.25 & 18.31 & 17.87 & 17.89 & 0.441 & 0.444 \\
\hline ADFI (g) & 517.41 & 534.41 & 496.54 & 508.78 & 16.040 & 0.442 \\
\hline ADG (g) & 306.16 & 335.68 & 321.99 & 334.02 & 7.034 & 0.053 \\
\hline$F / G$ & $1.69^{a}$ & $1.60^{a b}$ & $1.54^{b}$ & $1.52^{b}$ & 0.031 & 0.021 \\
\hline $\begin{array}{l}\text { Diarrhea } \\
\text { rate }\end{array}$ & $20.24^{a}$ & $17.86^{a b}$ & $13.53^{\mathrm{ab}}$ & $10.04^{b}$ & 2.217 & 0.041 \\
\hline
\end{tabular}

Control, basal diet. ZnSO4, basal diet+100mg/kg zinc sulphate. Gly-Zn, basal diet+100mg/kg glycine zinc. Zinc lactate, basal diet $+100 \mathrm{mg} / \mathrm{kg}$ zinc lactate. BW, body weight. ADFl, average daily feed intake. ADG, average daily gain. F/G, feed-to-gain ratio. SEM, standard error of the mean. a,b, Within a row, means without a common superscript letter differ $(P<0.05)$.
TABLE 5 | Effect of dietary zinc sources on the apparent total tract digestibility in weaned piglets.

\begin{tabular}{lcccccc}
\hline Items & Control & ZnSO4 & Gly-Zn & $\begin{array}{c}\text { Zinc } \\
\text { lactate }\end{array}$ & SEM & $P$ values \\
\hline EE & $71.32^{\mathrm{b}}$ & $76.44^{\mathrm{a}}$ & $77.72^{\mathrm{a}}$ & $78.84^{\mathrm{a}}$ & 0.954 & 0.002 \\
DM & $84.56^{\mathrm{b}}$ & $87.59^{\mathrm{a}}$ & $87.60^{\mathrm{a}}$ & $87.71^{\mathrm{a}}$ & 0.344 & 0.001 \\
Crude & $60.55^{\mathrm{b}}$ & $67.64^{\mathrm{a}}$ & $69.45^{\mathrm{a}}$ & $70.12^{\mathrm{a}}$ & 0.588 & $<0.0001$ \\
ash & & & & & & \\
CP & $77.35^{\mathrm{b}}$ & $80.97^{\mathrm{a}}$ & $80.63^{\mathrm{a}}$ & $81.73^{\mathrm{a}}$ & 0.544 & 0.001 \\
Zinc & $2.08^{\mathrm{c}}$ & $10.27^{\mathrm{c}}$ & $27.91^{\mathrm{b}}$ & $42.95^{\mathrm{a}}$ & 2.212 & $<0.0001$ \\
\hline
\end{tabular}

Control, basal diet. ZnSO4, basal diet $+100 \mathrm{mg} / \mathrm{kg}$ zinc sulphate. Gly-Zn, basal diet $+100 \mathrm{mg} / \mathrm{kg}$ glycine zinc. Zinc lactate, basal diet $+100 \mathrm{mg} / \mathrm{kg}$ zinc lactate. EE, ether extract; DM, dry matter; CP, crude protein. SEM, standard error of the mean. $a, b$, Within a row, means without a common superscript letter differ $(P<0.05)$.

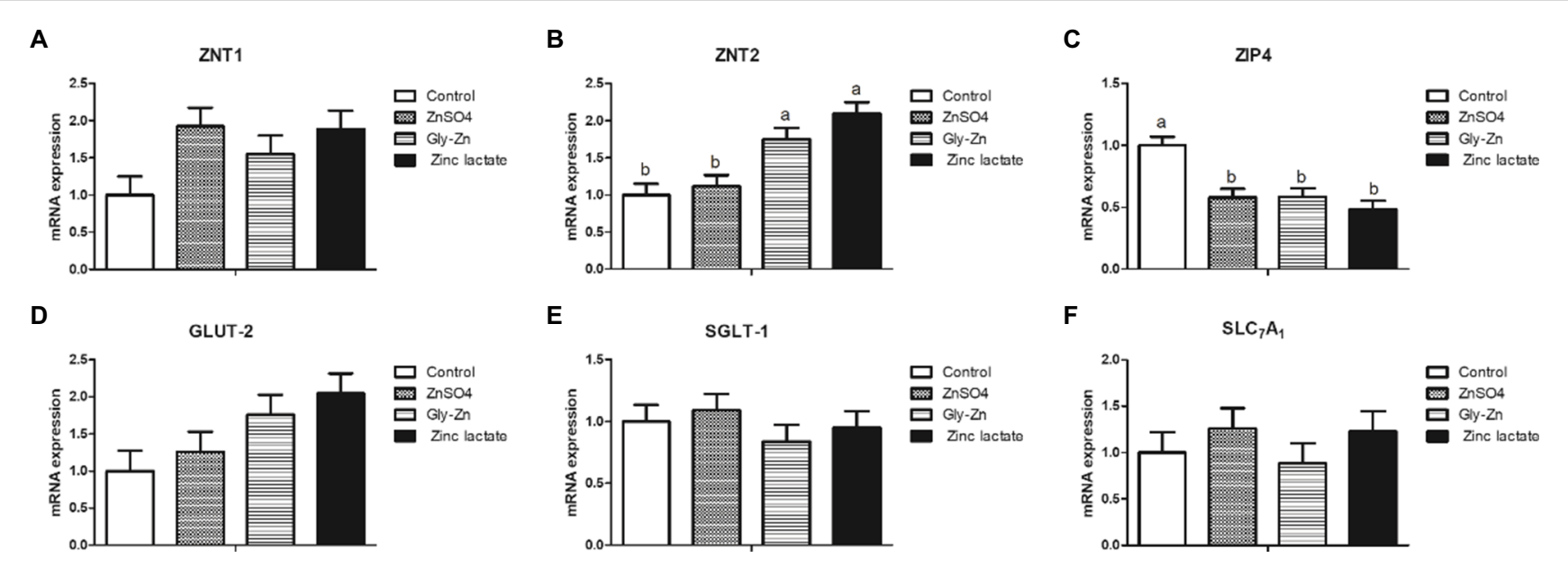

FIGURE 1 | Effect of dietary zinc sources on the relative mRNA expression levels of jejunal digestion- and absorption-related genes in weaned piglets. Control, basal diet. ZnSO4, basal diet $+100 \mathrm{mg} / \mathrm{kg}$ zinc sulphate. Gly-Zn, basal diet $+100 \mathrm{mg} / \mathrm{kg}$ glycine zinc. Zinc lactate, basal diet $+100 \mathrm{mg} / \mathrm{kg}$ zinc lactate. The relative mRNA expression levels of jejunal zinc transporter 1 (ZNT1; A), zinc transporter 2 (ZNT2; B), ZRT/IRT-like protein 4 (ZIP4; C), glucose transporter type 2 (GLUT-2; D), sodium/glucose cotransporter 1 (SGLT-1; E), and solute carrier family $7\left(\mathrm{SLC}_{7} \mathrm{~A}_{1} ; \mathbf{F}\right)$ were determined by real-time quantitative PCR. ${ }^{\text {abb }}$ Within a row, means without a common superscript letter differ $(p<0.05)$.

Gly-Zn, and zinc lactate groups than in the control group $(p<0.05)$. In addition, the mRNA expression level of jejunal IL-10 tended to be higher in the ZnSO4, Gly-Zn, and zinc lactate groups than in the control group $(p=0.087)$. The mRNA expression level of jejunal MUC2 was higher in the zinc lactate group than in the control group $(p<0.05)$. However, the mRNA expression level of jejunal MUC2 did not differ significantly among the $\mathrm{ZnSO} 4$, Gly-Zn, and control groups $(p>0.05)$.

As shown in Table 7, the total bacterial count in the cecal digesta was higher in the $\mathrm{ZnSO} 4, \mathrm{Gly}-\mathrm{Zn}$, and zinc lactate groups than in the control group $(p<0.05)$. The zinc lactate group had a higher count of Lactobacillus spp. in the cecal digesta than the control group $(p<0.05)$. However, the count of E. coli in the cecal digesta tended to be lower in the Gly-Zn and zinc lactate groups than in the control group $(p=0.075)$.

\section{DISCUSSION}

Zinc is a component of various enzymes in animals; it has important physiological and nutritional functions for animal growth, reproduction, and immunity. It also exhibits cell growthpromoting and antioxidant effects (Bonaventura et al., 2015). Zinc depletion tests have confirmed that zinc deficiency can result in lower ADG, decreased growth hormone synthesis, and reduced production of IGF-1 induced by growth hormone, thereby impairing the growth of piglets (Swinkels et al., 1996). In the present study, the ADG in the zinc supplementation groups ( $\mathrm{ZnSO} 4, \mathrm{Gly}-\mathrm{Zn}$, and zinc lactate groups) was higher than that in the control group, indicating a beneficial effect of zinc on growth performance. On comparing different zinc sources, organic zinc sources were found to have a relatively higher bioavailability than inorganic ones (Pearce et al., 2015; Li et al., 2018). In a previous study, weaned piglets fed $20-120 \mathrm{mg}$ 
TABLE 6 | Effect of dietary zinc sources on the intestinal morphology and number of goblet cells in weaned piglets.

\begin{tabular}{|c|c|c|c|c|c|c|}
\hline Items & Control & ZnSO4 & Gly-Zn & Zinc lactate & SEM & $P$ values \\
\hline \multicolumn{7}{|l|}{ Duodenum } \\
\hline Villus height, $\mu \mathrm{m}$ & 352.75 & 381.74 & 412.31 & 442.35 & 24.132 & 0.094 \\
\hline Crypt depth, $\mu \mathrm{m}$ & 145.74 & 139.89 & 142.07 & 144.08 & 6.417 & 0.925 \\
\hline Villus height: crypt depth & 2.59 & 2.74 & 2.91 & 2.95 & 0.206 & 0.602 \\
\hline \multicolumn{7}{|l|}{ Jejunum } \\
\hline Villus height, $\mu \mathrm{m}$ & $332.86^{b}$ & $354.33^{\mathrm{ab}}$ & $414.85^{\mathrm{a}}$ & $416.92^{\mathrm{a}}$ & 16.507 & 0.004 \\
\hline Crypt depth, $\mu \mathrm{m}$ & 159.69 & 125.63 & 140.91 & 126.22 & 9.649 & 0.079 \\
\hline Villus height: crypt depth & $2.46^{b}$ & $2.85^{\mathrm{ab}}$ & $2.95^{a}$ & $3.21^{\mathrm{a}}$ & 0.117 & 0.004 \\
\hline \multicolumn{7}{|l|}{ Ileum } \\
\hline Villus height, $\mu \mathrm{m}$ & 309.84 & 332.10 & 321.14 & 382.55 & 18.325 & 0.060 \\
\hline Crypt depth, $\mu \mathrm{m}$ & 146.44 & 148.79 & 147.40 & 139.51 & 7.486 & 0.822 \\
\hline Villus height: crypt depth & 2.66 & 2.78 & 2.69 & 3.07 & 0.132 & 0.152 \\
\hline Goblet cells & 316.56 & 339.56 & 330.67 & 387.72 & 17.856 & 0.064 \\
\hline
\end{tabular}

Control, basal diet. ZnSO4, basal diet $+100 \mathrm{mg} / \mathrm{kg}$ zinc sulphate. Gly-Zn, basal diet $+100 \mathrm{mg} / \mathrm{kg}$ glycine zinc. Zinc lactate, basal diet + $100 \mathrm{mg} / \mathrm{kg}$ zinc lactate. SEM, standard error of the mean. a,b, Within a row, means without a common superscript letter differ $(P<0.05)$.

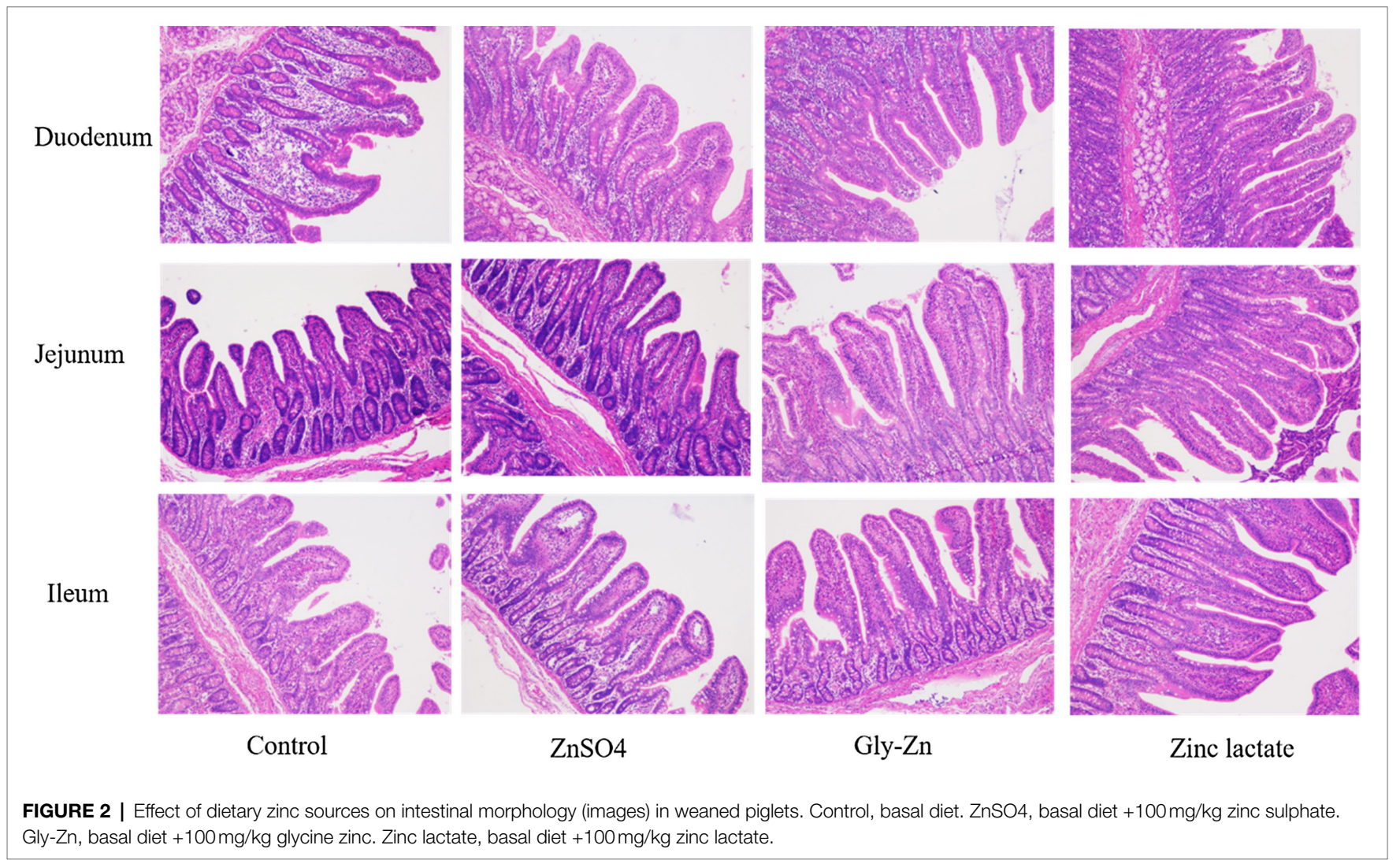

$\mathrm{Zn} / \mathrm{kg}$ in an organic form (zinc amino acid $[\mathrm{ZnAA}]$ ) were found to have a lower $F / G$ than those in the unsupplemented group, while no differences were noted between the inorganic zinc-supplemented and unsupplemented groups (Zhang et al., 2017). Under nursery conditions, dietary supplementation with $500 \mathrm{mg} / \mathrm{kg}$ polysaccharide zinc complex had the same effect as that supplemented with $3,000 \mathrm{mg} / \mathrm{kg}$ pharmacological zinc oxide on enhancing the growth performance of piglets (Case and Carlson, 2002). In another study, broilers fed diets supplemented with $60 \mathrm{mg} / \mathrm{kg} \mathrm{ZnAA}$ complexes had a lower $\mathrm{F} / \mathrm{G}$ in the starter phase than those fed diets supplemented with ZnSO4 (Chand et al., 2020; Grande et al., 2020). Similarly, the organic form of zinc (zinc lactate) was found to be superior in improving the growth of young grass carp (Song et al., 2017). In the present study, compared with the control group, the $F / G$ decreased in the organic zinc-supplemented groups (Gly- $\mathrm{Zn}$ and zinc lactate groups) from days 0 to 28; these findings are generally consistent with those of the aforementioned 
A

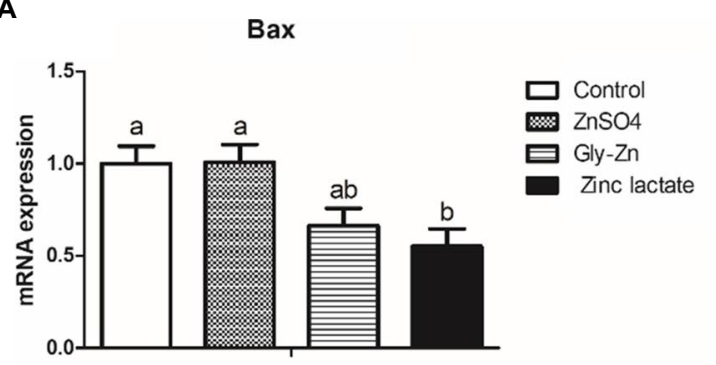

C

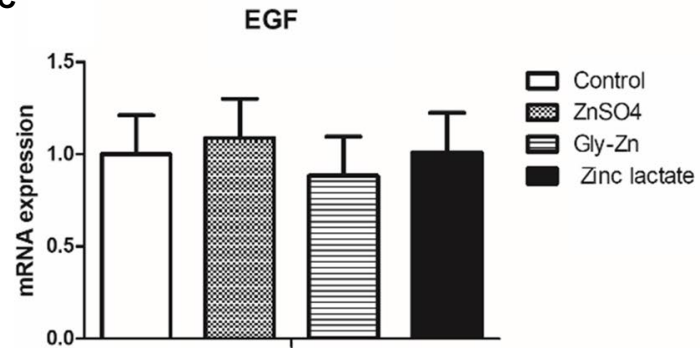

B

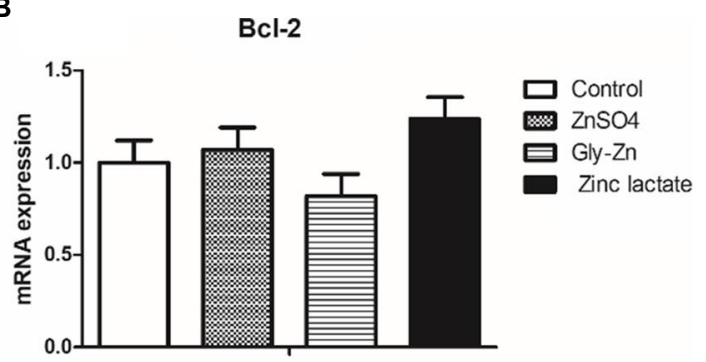

D

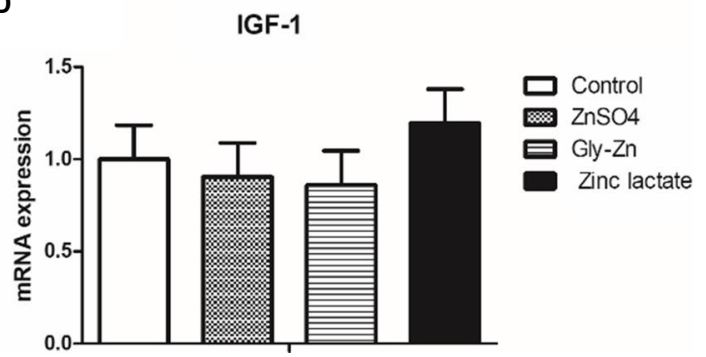

FIGURE 3 | Effect of dietary zinc sources on the relative messenger RNA (mRNA) expression levels of intestinal development-related genes in weaned piglets. Control, basal diet. ZnSO4, basal diet $+100 \mathrm{mg} / \mathrm{kg}$ zinc sulphate. Gly-Zn, basal diet $+100 \mathrm{mg} / \mathrm{kg}$ glycine zinc. Zinc lactate, basal diet $+100 \mathrm{mg} / \mathrm{kg}$ zinc lactate. The relative mRNA expression levels of jejunal Bcl-2-associated X protein (Bax; A), B-cell lymphoma/leukaemia-2 (Bcl-2; B), epidermal growth factor (IGF-1; C), and insulin-like growth factor-1 (IGF-1; D) were determined by real-time quantitative PCR. ${ }^{\text {a,b }}$ Within a row, means without a common superscript letter differ $(p<0.05)$.

studies. Moreover, zinc deficiency could alter paracellular ionic conductance, cause perturbed barrier integrity and reduce $\mathrm{Cl}^{-}$ secretion, resulting in increased susceptibility to infection (Sarkar et al., 2018). Thus, adequate levels are required to maintain the gut barrier, avoid risk intestinal infections, and prevent diarrhea. However, a lower diarrhea rate was observed only in the zinc lactate group in the present study, suggesting that zinc lactate has a more beneficial effect on intestinal health than Gly-Zn.

In the present study, the ATTD of DM, CP, EE, and crude ash was found to be increased in pigs fed $100 \mathrm{mg} / \mathrm{kg}$ zinc, regardless of the zinc source. However, the ATTD of zinc significantly differed among the three groups receiving dietary zinc supplementation; it was the highest in the zinc lactate group, followed by the Gly- $\mathrm{Zn}$ and $\mathrm{ZnSO} 4$ groups. In general, the improvement in nutrient digestibility is accompanied by the elevation in growth performance; this was mutually confirmed by improved growth performance in the present study. Consistent with our result, dietary supplementation with $60 \mathrm{mg} / \mathrm{kg} \mathrm{ZnAA}$ complexes was found to result in better digestibility of zinc than supplementation with $\mathrm{ZnSO} 4$ in young broilers in a previous study (Zhang et al., 2017). Supplementation with different zinc sources (zinc lactate, Gly-Zn, and ZnSO4) did not affect the digestibility of other nutrients (DM, CP, EE, and crude ash) in the present study; these findings are in accordance with those of previous studies comparing the supplementation of Gly-Zn and ZnSO4 (Ma et al., 2011; Kwiecień et al., 2017). The ZnT family, which is responsible for decreasing the concentration of zinc ions in the cytoplasm, and the ZIP family, which is responsible for increasing the concentration of zinc ions in the cytoplasm, play important roles in the absorption and transport of zinc ions (Nies, 2007). In the present study, dietary supplementation with $100 \mathrm{mg} / \mathrm{kg} \mathrm{ZnSO} 4$, Gly-Zn, or zinc lactate decreased the mRNA expression level of jejunal ZIP4 in weaned piglets. The mRNA expression level of jejunal ZNT2 was higher in the Gly-Zn and zinc lactate groups than in the control group; these findings are consistent with those of a previous in vitro study (Huang et al., 2016). A study conducted using a pig model also revealed that the addition of zinc lactate to the medium could upregulate the mRNA expression level of ZNT2 and downregulate the mRNA expression level of ZIP4 (Wang et al., 2014). It has been reported that zinc has acquired an insulin-like activity (Tang and Shay, 2001). A higher mRNA expression level of jejunal GLUT-2 was observed in the Gly-Zn and zinc lactate groups in the present study, indicating that organic zinc may stimulate higher glucose transporter expression and lower blood glucose levels.

Weaning stress disturbs the intestinal health balance, which is characterized by villous atrophy and crypt hyperplasia, in addition to a reduction in epithelial brush border activity and nutrient digestibility (Montagne et al., 2003; Wang et al., 2006). Consequently, maintaining intestinal morphological properties for digesting various nutrients after weaning is important. In the present study, the jejunal villus height and villus height:crypt depth ratio were higher in the Gly- $\mathrm{Zn}$ and zinc lactate groups than in the control group. Moreover, the villus heights of the duodenum and ileum were higher in the zinc lactate group than in the control group. In accordance with our findings, dietary supplementation with $100 \mathrm{mg} / \mathrm{kg}$ zinc lactate was found 
A

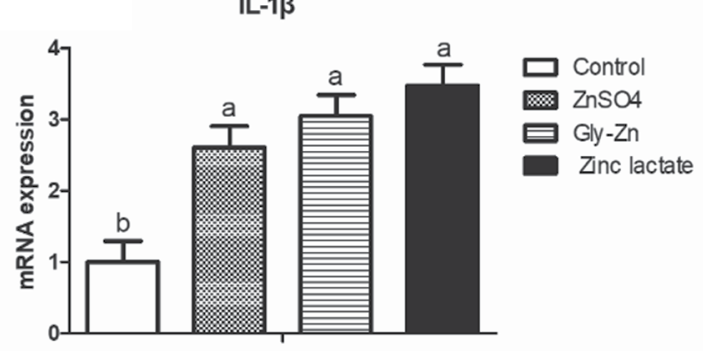

C

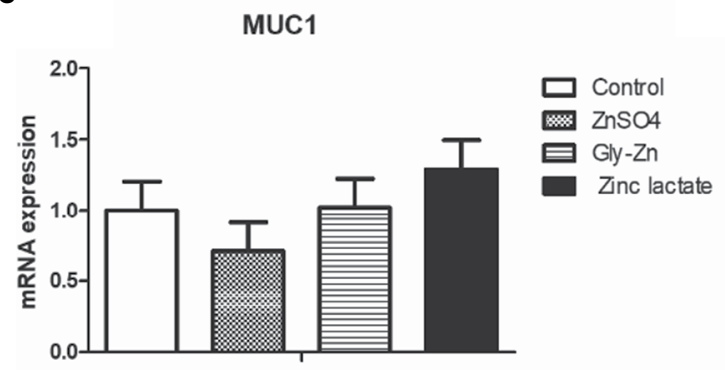

B

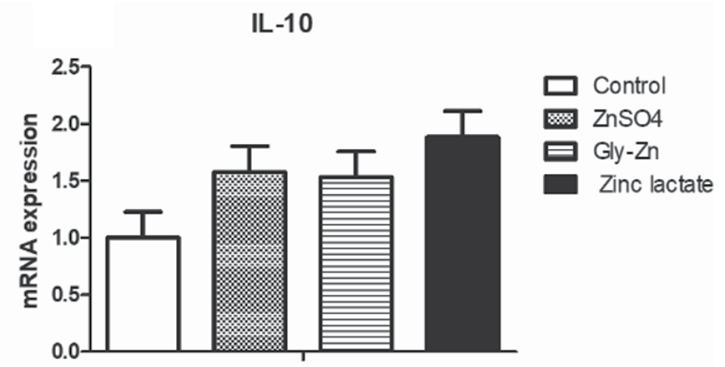

D

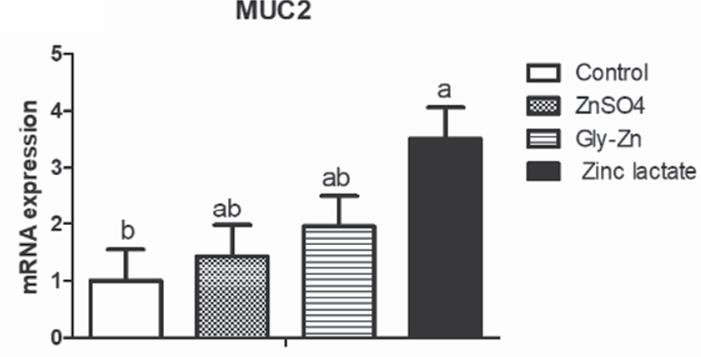

E

Occludin

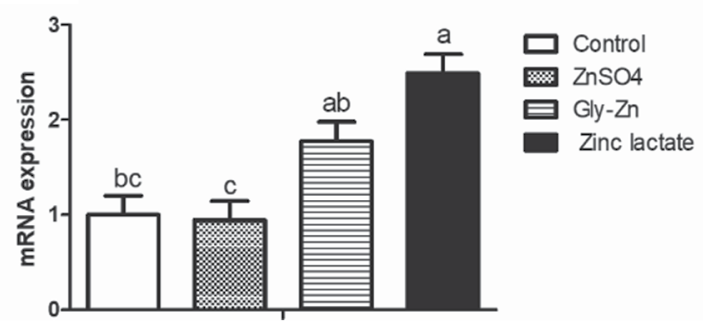

FIGURE 4 | Effect of dietary zinc sources on the relative mRNA expression levels of jejunal barrier-related genes in weaned piglets. Control, basal diet. ZnSO4, basal diet $+100 \mathrm{mg} / \mathrm{kg}$ zinc sulphate. Gly-Zn, basal diet $+100 \mathrm{mg} / \mathrm{kg}$ glycine zinc. Zinc lactate, basal diet $+100 \mathrm{mg} / \mathrm{kg}$ zinc lactate. The relative mRNA expression

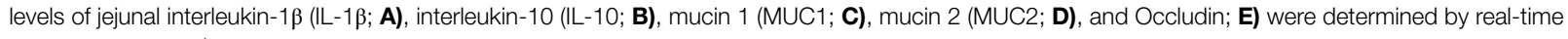
quantitative PCR. ${ }^{a, b}$ Within a row, means without a common superscript letter differ $(p<0.05)$.

TABLE 7 | Effect of dietary zinc source on the numbers of Escherichia coli, Lactobacilli spp., Bifidobacterium spp., and Bacillus spp. in the cecal digesta of weaned piglets (log [copies/g]).

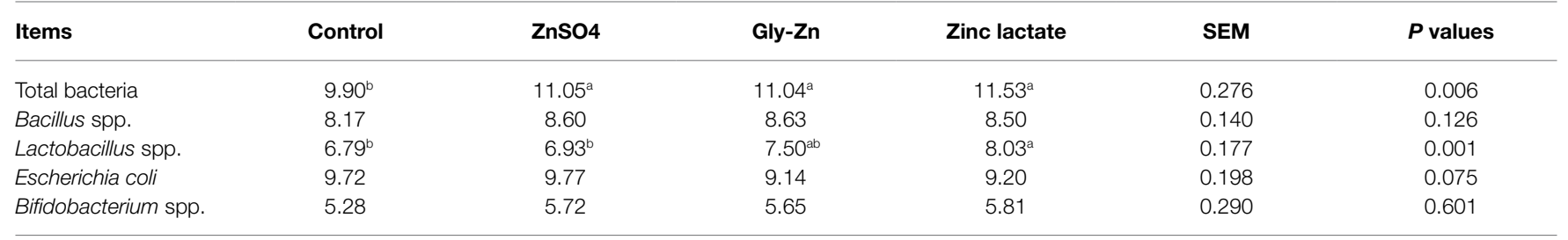

Control, basal diet. ZnSO4, basal diet $+100 \mathrm{mg} / \mathrm{kg}$ zinc sulphate. Gly-Zn, basal diet + 100 mg/kg glycine zinc. Zinc lactate, basal diet + 100 mg/kg zinc lactate. SEM, standard error of the mean. a,b Within a row, means without a common superscript letter differ $(p<0.05)$.

to significantly increase the villus height and decrease the crypt depth of the duodenum, jejunum, and ileum in weaned piglets in a previous study, thereby improving the morphology and function of the intestinal epithelium (Wang et al., 2014). Similarly, dietary supplementation with $90 \mathrm{mg} / \mathrm{kg}$ Gly-Zn increased the villus height of the duodenum and jejunum and decreased the crypt depth of the jejunum and ileum in 42-dayold chickens in another study (Ma et al., 2011). Intestinal morphology is directly proportional to digestibility and, consequently, to feed conversion efficiency (Collett, 2012). 
Therefore, the improved intestinal morphology may partly explain the lowered $F / G$ and increased digestibility of zinc on dietary supplementation with Gly-Zn or zinc lactate. On the other hand, the improvement in intestinal epithelial morphology caused by supplementation with organic zinc may be related to the promotion of intestinal epithelial cell development. In vitro, zinc lactate could significantly promote the proliferation of the porcine jejunal epithelial cells IPEC-J2 after $48 \mathrm{~h}$ of inoculation, and the proliferation amplitude was elevated with an increase in zinc lactate concentrations (Han et al., 2012). Meanwhile, zinc lactate could significantly reduce the cell apoptosis rate and the expression level of apoptotic protein in IPEC-J2 cells induced by hydrogen peroxide (Tang et al., 2020). In our present study, a lower mRNA expression level of jejunal Bax (a pro-apoptotic gene) was observed in the zinc lactate group, indicating that zinc lactate may promote intestinal morphology by promoting cell proliferation and inhibiting cell apoptosis.

Intestinal barrier integrity is primarily maintained by the tight junctions. Zinc deficiency causes the release of zinc bound to proteins and increases the content of free zinc in the cytoplasm, resulting in the inhibition of cell growth, disruption of tight junction proteins, and the subsequent impairment of intestinal barrier function (Zhong et al., 2010). In an in vitro study, compared with $\mathrm{ZnSO} 4,300 \mu \mathrm{mol}$ zinc butyrate could increase transmembrane resistance and maintain the integrity of tight junctions in IPEC-J2 cells, indicating that zinc butyrate could alleviate the increased permeability of IPEC-J2 cells induced by heat stress (Mani et al., 2019). Sanz Fernandez et al. (2014) revealed that the transepithelial resistance of the ileum was $56 \%$ higher in the $\mathrm{ZnAA}$ complex group than in the $\mathrm{ZnSO} 4$ group (Fernandez et al., 2014). In grass carp, compared with the $56.9 \mathrm{mg} / \mathrm{kg}$ $\mathrm{ZnSO} 4$ group, dietary supplementation with $49.84 \mathrm{mg} / \mathrm{kg}$ zinc lactate upregulated the mRNA expression levels of occludin, ZO-1, claudin-B, claudin-C, claudin-F, claudin-3, claudin-7A, claudin-7B, claudin-11, claudin-12, and claudin-15A genes in the intestine (Song et al., 2017). Consistent with previous findings, we found that the mRNA expression level of the jejunal occludin was higher in the zinc lactate group than in the control and $\mathrm{ZnSO} 4$ groups. Myosin light-chain kinase (MLCK) is the most important calmodulin kinase affecting the barrier function of the intestinal mucosal epithelium (Nalle et al., 2011). Tumor necrosis factor- $\alpha$ (TNF- $\alpha$ ) induces the expression of MLCK and phosphorylated myosin light chains, resulting in a loss of intercellular tight junctions and further increasing intestinal epithelial permeability through paracellular pathways (Mckenzie and Ridley, 2007). Previous studies have demonstrated that organic zinc can downregulate the expression of TNF- $\alpha$ in the intestine (Li, 2015; Song et al., 2017). Therefore, it is speculated that organic zinc can maintain the normal tight junctions of intestinal epithelial cells by inhibiting the TNF- $\alpha$-induced upregulation of MLCK expression.

Among the chemical barrier components of the intestinal mucosa, MUC2, which is mainly secreted by cup cells, is the main component of intestinal mucus and plays an important role in lubricating the intestinal tract, in providing adhesion sites for intestinal antibacterial proteins and symbiotic flora and in resisting the invasion of intestinal pathogens and harmful substances (Hasnain et al., 2010). Compared with $\mathrm{ZnSO} 4$, protein-chelated zinc was found to significantly increase the number of intraepithelial goblet cells in the duodenum and jejunum of growing-finishing pigs (Zhou, 2009). In a previous study, dietary supplementation with $30 \mathrm{mg} / \mathrm{kg}$ Gly-Zn or $\mathrm{ZnSO} 4$ upregulated the mRNA expression level of jejunal MUC2 in broilers. The mRNA expression level of MUC2 in the Gly-Zn group tended to be higher than that in the $\mathrm{ZnSO} 4$ group (Levkut et al., 2017); these findings are in accordance with those of the present study. In the present study, supplementation with zinc lactate increased the number of goblet cells in the ileum and upregulated the transcription level of MUC2 in the intestine, indicating that zinc lactate could also improve the intestinal chemical barrier function in weaned piglets.

The intestinal tract is the largest organ in the immune system of animals, and maintaining normal intestinal barrier function is extremely important for good intestinal health (Chassaing et al., 2014). Long-term zinc deficiency leads to the infiltration of inflammatory cells, particularly the uncontrolled migration of epithelial multinucleated lymphocytes, in the intestinal mucosa, thereby inducing mucosal injury and damaging the intestinal immune barrier (Finamore et al., 2008). Moreover, zinc deficiency can reduce the proliferation of $\mathrm{T}$ lymphocytes and $\mathrm{B}$ lymphocytes in mice, weaken their ability to deal with the invasion of exogenous pathogenic microorganisms and damage their immune system (Srinivas et al., 1989). Cytokines have momentous effects on immune responses and are involved in regulating intestinal barrier integrity (Al-Sadi, 2009). Zinc promotes the adhesion of monocytes to endothelial cells; this is important for the production of inflammatory cytokines, such as IL-1 $\beta$, IL-6, and TNF- $\alpha$ (Chavakis et al., 1999). Consistently, higher mRNA expression levels of jejunal $I L-1 \beta$ and $I L-10$ were observed following zinc supplementation in the present study, indicating that dietary supplementation with $100 \mathrm{mg} / \mathrm{kg}$ zinc can improve intestinal immune function in weaned piglets. Very limited studies have assessed the effects of different zinc sources on the intestinal immune barrier. In grass carp, compared with the $56.9 \mathrm{mg} / \mathrm{kg} \mathrm{ZnSO} 4$ group, dietary supplementation with $49.84 \mathrm{mg} / \mathrm{kg}$ zinc lactate was found to upregulate the mRNA expression level of $I L-10$ in the intestine (Song et al., 2017). However, there was no difference in the effect of different zinc sources on inflammatory cytokines; this could be related to zinc levels, animal species, period, and health status, among others.

The digestive tract of animals has evolved into a key site for the coexistence of nutrients and microorganisms. The intestinal biological barrier is formed by a large number of normal microflora, and the intestinal microecological balance is crucial for the normal function of the intestinal biological barrier (Shanahan, 2002). Zinc is an essential mineral element involved in the colonization and proliferation of microorganisms in the host. Chronic dietary zinc depletion induces significant 
taxonomic alterations in the intestinal microflora and decreases the overall species richness and diversity, thereby establishing a microbial profile resembling that of various pathological states (Spenser et al., 2015). In the present study, dietary supplementation with $100 \mathrm{mg} / \mathrm{kg}$ zinc increased the total bacterial count in the cecal digesta of weaned piglets. As we did not assess the microbial diversity in the cecal digesta, the effects of different zinc sources on the intestinal microbial diversity need to be studied further. Another intriguing finding of the present study was that the count of Lactobacillus spp. in the cecal digesta was higher in the zinc lactate group than in the control group. Moreover, the count of E. coli in the cecal digesta was lower in the Gly-Zn and zinc lactate groups than in the control group. The alteration in and balance between beneficial bacteria (such as Lactobacillus spp.) and harmful bacteria (such as pathogenic E. coli) in the gut are associated with the gut health of the host (Diao et al., 2015). E. coli has been reported to destabilize and dissociate tight junction proteins (Muza-Moons et al., 2004). In the present study, the increased mRNA expression level of the occludin gene observed in the zinc lactate group was in accordance with the decreased $E$. coli count. Collectively, these findings suggest that zinc lactate could maintain the balance of the gut microbiota and improve the intestinal barrier.

\section{CONCLUSION}

In conclusion, dietary supplementation with $100 \mathrm{mg} / \mathrm{kg} \mathrm{ZnSO} 4$, Gly-Zn, or zinc lactate could improve the growth performance of weaned pigs, at least partly, by improving the digestion of nutrients, intestinal morphology, and barrier function. Dietary supplementation with organic zinc, particularly zinc lactate, was found to have the best effect. However, the mRNA expression levels of zinc transporters were not consistent between the groups receiving dietary supplementation with inorganic and organic zinc, indicating possible differences in the absorption and transport channels.

\section{REFERENCES}

Alam, A. N., Sarker, S. A., Wahed, M. A., Khatun, M., and Rahaman, M. M. (1994). Enteric protein loss and intestinal permeability changes in children during acute shigellosis and after recovery: effect of zinc supplementation. Gut 35, 1707-1711. doi: 10.1136/gut.35.12.1707

Al-Sadi, R. (2009). Mechanism of cytokine modulation of epithelial tight junction barrier. Front. Biosci. 14, 2765-2778. doi: 10.2741/3413

Andreini, C., Banci, L., Bertini, I., and Rosato, A. (2006). Counting the zincproteins encoded in the human genome. J. Proteome Res. 5, 196-201. doi: $10.1021 / \mathrm{pr} 050361 \mathrm{j}$

AOAC. (1995). "Official methods of analysis," in Association of Official Analytical Chemists. 16th Edn. Washington, DC, USA.

Blikslager, A. T., Moeser, A. J., Gookin, J. L., Jones, S. L., and Odle, J. (2007). Restoration of barrier function in injured intestinal mucosa. Physiol. Rev. 87, 545-564. doi: 10.1152/physrev.00012.2006

Bonaventura, P., Benedetti, G., Albarède, F., and Miossec, P. (2015). Zinc and its role in immunity and inflammation. Autoimmun. Rev. 14, 277-285. doi: 10.1016/j.autrev.2014.11.008

Campbell, J. M., Crenshaw, J. D., and Polo, J. (2013). The biological stress of early weaned piglets. J. Anim. Sci. Biotechnol. 4, 45-48. doi: 10.1186/20491891-4-19

\section{DATA AVAILABILITY STATEMENT}

The original contributions presented in the study are included in the article/supplementary material, further inquiries can be directed to the corresponding author.

\section{ETHICS STATEMENT}

The animal study was reviewed and approved by Animal Care Advisory Committee of Sichuan Academy of Animal Science.

\section{AUTHOR CONTRIBUTIONS}

HD, JY, and SL conceived the study, designed, and performed the experiments, including chemical analysis, analyzed the experimental data, and wrote the manuscript. WT was responsible for conceptualization. SK and JZ verified the validity of the experiments and checked the results. $\mathrm{XW}, \mathrm{MZ}, \mathrm{CH}$, and $\mathrm{PH}$ participated in the experimental design and gave important intellectual advice for approval. All the authors read and approved the final version of the manuscript.

\section{FUNDING}

The present study was financially supported by the Sichuan Science and Technology Programmes (2020YFH0170, 2021ZHYZ0005, and 2021NZZJ0019).

\section{ACKNOWLEDGMENTS}

The authors wish to thank GW Zhang and ZG Luo from the College of Animal Science, Southwest University, for the elaborate animal examination and surgery.

Case, C., and Carlson, M. (2002). Effect of feeding organic and inorganic sources of additional zinc on growth performance and zinc balance in nursery pigs. J. Anim. Sci. 80, 1917-1924. doi: 10.2527/2002.8071917x

Chand, N., Zahirullah, R. U. K., Shah, M., Naz, S., and Tinelli, A. (2020). Zinc source modulates zootechnical characteristics, intestinal features, humoral response, and paraoxonase (PON1) activity in broilers. Trop. Anim. Health Prod. 52, 511-515. doi: 10.1007/s11250-019-02036-4

Chassaing, B., Kumar, M., Baker, M. T., Singh, V., and Vijay-Kumar, M. (2014). Mammalian gut immunity, Mammalian gut immunity. Biomed. J. 37, 246-258. doi: $10.4103 / 2319-4170.130922$

Chavakis, T., May, A. E., Preissner, K. T., and Kanse, S. M. (1999). Molecular mechanisms of zinc-dependent leukocyte adhesion involving the urokinase receptor and $\beta 2$-Integrins. Blood 93, 2976-2983. doi: 10.1182/blood.V93.9.2976

Collett, S. R. (2012). Nutrition and wet litter problems in poultry. Anim. Feed Sci. Technol. 173, 65-75. doi: 10.1016/j.anifeedsci.2011.12.013

Diao, H., Gao, Z. B., Yu, B., Zheng, P., He, J., Yu, J., et al. (2017). Effects of benzoic acid (VevoVitall) on the performance and jejunal digestive physiology in young pigs. J. Anim. Sci. Biotechnol. 7, 32-160. doi: 10.1186/s40104-016-0091-y

Diao, H., Zheng, P., Yu, B., He, J., Mao, X. B., Yu, J., et al. (2015). Effects of benzoic acid and thymol on growth performance and gut characteristics of weaned piglets. Asian Austral. J. Anim. Sci. 28, 827-839. doi: 10.5713/ ajas.14.0704 
Fernandez, M. V. S., Pearce, S. C., Gabler, N. K., Patience, J. F., and Baumgard, L. H. (2014). Effects of supplemental zinc amino acid complex on gut integrity in heat-stressed growing pigs. Animal 8, 43-50. doi: 10.1017/S1751731113001961

Fierer, N., Jackson, J. A., Vilgalys, R., and Jackson, R. B. (2005). Assessment of soil microbial community structure by use of taxon-specific quantitative PCR assays. Appl. Environ. Microbiol. 71, 4117-4120. doi: 10.1128/ AEM.71.7.4117-4120.2005

Finamore, A., Massimi, M., Conti Devirgiliis, L., and Mengheri, E. (2008). Zinc deficiency induces membrane barrier damage and increases neutrophil transmigration in Caco-2 cells. J. Nutr. 138, 1664-1670. doi: 10.1093/ jn/138.9.1664

Grande, A. D., Leleu, S., Delezie, E., Rapp, C., and Ducatelle, R. (2020). Dietary zinc source impacts intestinal morphology and oxidative stress in young broilers. Poult. Sci. 99, 441-453. doi: 10.3382/ps/pez525

Han, G. Q., Yu, B., Chen, D. W., Xiang, Z. T., Qi, H. W., Chen, H., et al. (2012). Effect of zinc lactate on cell proliferation and related-regulator genes mRNA expression in porcine jejunal epithelial cells IPEC-J2. Acta Veterinaria et Zootechnica Sinica. 43, 740-747.

Hart, G. K., and Dobb, G. J. (1988). Effect of a fecal bulking agent on diarrhea during enteral feeding in the critically Ill. JPEN-Parenter Enter. 12, 465-468. doi: 10.1177/0148607188012005465

Hasnain, S. Z., Wang, H., Ghia, J. E., Haq, N., Deng, Y., Velcich, A., et al. (2010). Mucin gene deficiency in mice impairs host resistance to an enteric parasitic infection. Gastroenterology 138, 1763.e5-1771.e5. doi: 10.1053/j. gastro.2010.01.045

Hu, C. H., Xiao, K., Luan, Z. S., and Song, J. (2013). Early weaning increases intestinal permeability, alters expression of cytokine and tight junction proteins, and activates mitogen-activated protein kinases in pigs. J. Anim. Sci. 91, 1094-1101. doi: 10.2527/jas.2012-5796

Huang, C., Qiao, S., Li, D., Piao, X., and Ren, J. (2004). Effects of lactobacilli on the performance, diarrhea incidence, VFA concentration and gastrointestinal microbial flora of weaning pigs. Asian Austral. J. Anim. Sci. 17, 401-409. doi: 10.5713/ajas.2004.401

Huang, D., Zhuo, Z., Fang, S., Yue, M., and Feng, J. (2016). Different zinc sources have diverse impacts on gene expression of zinc absorption related transporters in intestinal porcine epithelial cells. Biol. Trace Elem. Res. 173, 325-332. doi: 10.1007/s12011-016-0655-x

Karl Kunzelmann, M. M. (2002). Electrolyte transport in the mammalian colon: mechanisms and implications for disease. Physiol. Rev. 82, 245-289. doi: 10.1152/physrev.00026.2001

Kunert, K. S., Tisdale, A. S., and Gipson, I. K. (2002). Goblet cell numbers and epithelial proliferation in the conjunctiva of patients with dry eye syndrome treated with cyclosporine. Arch. Ophthalmol. 120, 330-337. doi: 10.1001/archopht.120.3.330

Kwiecień, M. G., Winiarska-Mieczan, A., Milczarek, A., and Klebaniuk, R. (2017). Biological response of broiler chickens to decreasing dietary inclusion levels of zinc glycine chelate. Biol. Trace Elem. Res. 175, 204-213. doi: 10.1007/s12011-016-0743-y

Levkut, M., Husáková, E., Bobíková, K., Karaffová, V., Levkutová, M., Ivanišinová, O., et al. (2017). Inorganic or organic zinc and MUC-2, IgA, IL-17, TGF- $\beta 4$ gene expression and sIgA secretion in broiler chickens. Food Agric. Immunol. 28, 801-811. doi: 10.1080/09540105.2017.1313202

Li, C.W. (2015). Effects of dietary zinc nutrition of the broiler breeders on the immunity function of their offsprings and the related molecular mechanism. docter's thesis. Beijing. China Agricultural University.

Li, L. L., Gong, Y. J., Zhan, H. Q., Zheng, Y. X., and Zou, X. T. (2018). Effects of dietary Zn-methionine supplementation on the laying performance, egg quality, antioxidant capacity, and serum parameters of laying hens. Poult. Sci. 98, 923-931. doi: 10.3382/ps/pey440

Ma, W., Niu, H., Feng, J., Wang, Y., and Feng, J. (2011). Effects of zinc glycine chelate on oxidative stress, contents of trace elements, and intestinal morphology in broilers. Biol. Trace Elem. Res. 142, 546-556. doi: 10.1007/ s12011-010-8824-9

Mani, V., Rubach, J. K., Sanders, D. J., Pham, T., Koltes, D. A., Gabler, N. K., et al. (2019). Evaluation of the protective effects of zinc butyrate in IPEC-J2 cells and grower pigs under heat stress. Transl. Anim. Sci. 3, 842-854. doi: $10.1093 /$ tas/txz023
Mckenzie, J. A. G., and Ridley, A. J. (2007). Roles of Rho/ROCK and MLCK in TNF- $\alpha$-induced changes in endothelial morphology and permeability. J. Cell. Physiol. 213, 221-228. doi: 10.1002/jcp.21114

Mclamb, B. L., Gibson, A. J., Overman, E. L., Stahl, C., Moeser, A. J., and Colette, K. L. (2013). Early weaning stress in pigs impairs innate mucosal immune responses to enterotoxigenic E. coli challenge and exacerbates intestinal injury and clinical disease. PloS One 8:e59838. doi: 10.1371/journal. pone. 0059838

Montagne, L., Pluske, J. R., and Hampson, D. J. (2003). A review of interactions between dietary fibre and the intestinal mucosa, and their consequences on digestive health in young non-ruminant animals. Anim. Feed Sci. Technol. 108, 95-117. doi: 10.1016/S0377-8401(03)00163-9

Muza-Moons, M. M., Schneeberger, E. E., and Hecht, G. A. (2004). Enteropathogenic Escherichia coli infection leads to appearance of aberrant tight junctions strands in the lateral membrane of intestinal epithelial cells. Cell. Microbiol. 6, 783-793. doi: 10.1111/j.1462-5822.2004.00404.x

Nalle, S. C., Joseph, N. E., Savage, P. A., and Turner, J. R. (2011). Intestinal damage and myosin light chain kinase (MLCK)-dependent epithelial barrier dysfunction are vital to minor mismatch graft-versus-host disease. Gastroenterology 140:167. doi: 10.1016/S0016-5085(11)60677-X

National Research Council. 2012. Nutrient Requirements of Swine. 11th Edn. Washington, DC, USA: National Academy Press.

Nies, D. H. (2007). Biochemistry. How cells control zinc homeostasis. Science. 317, 1695-1696. doi: 10.1126/science.1149048

Pearce, C., Fernandez, M. V. S., Torrison, J., Wilson, M. E., and Gabler, N. K. (2015). Dietary organic zinc attenuates heat stress-induced changes in pig intestinal integrity and metabolism. J. Anim. Sci. 93, 4702-4713. doi: 10.2527/ jas.2015-9018

Qi, H. W., Xiang, Z. T., Han, G. Q., Yu, B., Huang, Z. Q., and Chen, D. W. (2011). Effects of different dietary protein sources on cecal microflora in rats. Afri. J. Biotechnol. 11, 3704-3708. doi: 10.1186/1472-6750-11-46

Rodriguez, P., Darmon, N., Chappuis, P., Candalh, C., Blaton, M. A., Bouchaud, C., et al. (1996). Intestinal paracellular permeability during malnutrition in Guinea pigs: effect of high dietary zinc. Gut 39, 416-422. doi: 10.1136/ gut.39.3.416

Sandra, V. E., Laila, P. J. F. D., Anna, V., Sandra, V. K., Diego, M. D., and David, S. O. (2020). Effects of copper and zinc sources and inclusion levels of copper on weanling pig performance and intestinal microbiota. J. Anim. Sci. 98:117. doi: 10.1093/jas/skaa117

Sarkar, P., Saha, T., Aoun, J., Chakraborty, S. H., Chakrabarti, M. K., Dutta, S. K., et al. (2018). Evidence that zinc deficiency impairs gut epithelial barrier and intestinal immunity. FASEB J. 32, 716-747. doi: 10.1096/fasebj.2018.32.1_ supplement.747.16

Shanahan, F. (2002). The host-microbe interface within the gut. Best Pract. Res. Clin. Gastroenterol. 16, 915-931. doi: 10.1053/bega.2002.0342

Song, Z. X., Jiang, W. D., Liu, Y., Wu, P., Jiang, J., Zhou, X. Q., et al. (2017). Dietary zinc deficiency reduced growth performance, intestinal immune and physical barrier functions related to NF-אB, TOR, Nrf2, JNK and MLCK signaling pathway of young grass carp (Ctenopharyngodon idella). Fish Shellfish Immunol. 66, 497-523. doi: 10.1016/j.fsi.2017.05.048

Spenser, R., Hadar, N., Sharon, M., Raymond, G., Omry, K., and Elad, T. (2015). Chronic zinc deficiency alters chick gut microbiota composition and function. 12th European nutrition Connference. Nutrients 7, 9768-9784. doi: $10.3390 /$ nu7125497

Srinivas, U., Braconier, J. H., Jeppsson, B., and Hansson, L. (1989). Influence of zinc deficiency and malnutrition on organ uptake of Eschericia coli during gram-negative sepsis in the rat. Nutr. Res. 9, 455-463. doi: 10.1016/ S0271-5317(89)80122-8

Swinkels, J. W., Kornegay, E. T., Zhou, W., Lindemann, M. D., Webb, K. E., and Verstegen, M. W. (1996). Effectiveness of a zinc amino acid chelate and zinc sulfate in restoring serum and soft tissue zinc concentrations when fed to zinc-depleted pigs. J. Anim. Sci. 74, 2420-2430. doi: 10.2527/1996.74102420x

Tang, W. J., Jing, L., Li, T. J., Yang, L. Y., and Yin, Y. L. (2020). The associated regulatory mechanisms of zinc lactate in redox balance and mitochondrial function of intestinal porcine epithelial cells. Oxidative Med. Cell. Longev. 2020, 1-15. doi: 10.1155/2020/8815383

Tang, X. H., and Shay, N. F. (2001). Zinc has an insulin-like effect on glucose transport mediated by phosphoinositol-3-kinase and akt in 3T3-L1 
fibroblasts and adipocytes. J. Nutr. 131, 1414-1420. doi: 10.1093/jn/131. 5.1414

Torsten, K., Shaun, V. W., Chen, J., Parkos, C. A., and Nusrat, A. (2001). Neutrophil transmigration in inflammatory bowel disease is associated with altered expression of intercellular junction proteins. Am. J. Pathol. 159, 2001-2009. doi: 10.1016/S0002-9440(10)63051-9

Turner, J. R. (2006). Molecular basis of epithelial barrier regulation: from basic mechanisms to clinical application. Am. J. Pathol. 169, 1901-1909. doi: 10.2353/ajpath.2006.060681

Vallee, B. L., and Falchuk, K. H. (1993). The biochemical basis of zinc physiology. Physiol. Rev. 73, 79-118. doi: 10.1152/physrev.1993.73.1.79

Wang, Y., Shan, T., Xu, Z., Liu, J., and Feng, J. (2006). Effect of lactoferrin on the growth performance, intestinal morphology, and expression of PR-39 and protegrin-1 genes in weaned piglets. J. Anim. Sci. 84, 2636-2641. doi: 10.2527/jas.2005-544

Wang, R., Xin, A., Zhang, C., Li, M. Q., Mei, W., An, Q. C., et al. (2014). Effects of zinc lactate on intestinal morphology, mRNA expressions of metallothioneins 1 in intestinal mucosa and acute phase proteins in tissues of weaner piglets. Chin. J. Anim. Nutr. 26, 1068-1076. doi: 10.3969/j. issn.1006-267x.2014.04.028

Yan, J. Y., Zhang, G. W., Zhang, C., Tang, L., and Kuang, S. Y. (2017). Effect of dietary organic zinc sources on growth performance, incidence of diarrhoea, serum and tissue zinc concentrations, and intestinal morphology in growing rabbits. World Rabbit Sci. 25, 43-49. doi: 10.4995/wrs.2017.5770

Zhang, B., and Guo, Y. (2009). Supplemental zinc reduced intestinal permeability by enhancing occludin and zonula occludens protein-1 (ZO-1) expression in weaning piglets. Br. J. Nutr. 102, 687-693. doi: 10.1017/S0007114509289033

Zhang, Y., Ward, T. L., Ji, F., Peng, C., and Dong, B. (2017). Effects of zinc sources and levels of zinc amino acid complex on growth performance, hematological and biochemical parameters in weanling pigs. Asian Austral. J. Anim. Sci. 31, 1267-1274. doi: 10.5713/ajas.17.0739

Zhao, Y., Yu, B., Mao, X., He, J., Huang, Z., Zheng, P., et al. (2015). Dietary vitamin $\mathrm{D}$ supplementation attenuates immune responses of pigs challenged with rotavirus potentially through the retinoic acid-inducible gene I signalling pathway. Br. J. Nutr. 112, 381-389. doi: 10.1017/ S000711451400097X

Zhong, W., Mcclain, C. J., Cave, M., Kang, Y. J., and Zhou, Z. (2010). The role of zinc deficiency in alcohol-induced intestinal barrier dysfunction. Am. J. Physiol. Gastrointest. Liver Physiol. 298, G625-G633. doi: 10.1152/ ajpgi.00350.2009

Zhou, L.H. (2009). Effects of copper and zinc protein chelate on immune performance in growth-finishing swine. master's thesis. Nanjing. Nanjing Agricultural University.

Conflict of Interest: Author SL was employed by company Sichuan Animtech Biology Development Co., Ltd. Author SK was employed by company Sichuan Animtech Feed Co., Ltd.

The remaining authors declare that the research was conducted in the absence of any commercial or financial relationships that could be construed as a potential conflict of interest.

Publisher's Note: All claims expressed in this article are solely those of the authors and do not necessarily represent those of their affiliated organizations, or those of the publisher, the editors and the reviewers. Any product that may be evaluated in this article, or claim that may be made by its manufacturer, is not guaranteed or endorsed by the publisher.

Copyright @ 2021 Diao, Yan, Li, Kuang, Wei, Zhou, Zhang, Huang, He and Tang. This is an open-access article distributed under the terms of the Creative Commons Attribution License (CC BY). The use, distribution or reproduction in other forums is permitted, provided the original author(s) and the copyright owner(s) are credited and that the original publication in this journal is cited, in accordance with accepted academic practice. No use, distribution or reproduction is permitted which does not comply with these terms. 